Figure 1 illustrates the major data f rom the experiment: Carbachol-drinking postlesion in the LHA lesioned group dropped to zero $1 / 2 \mathrm{~h}$ following lesioning and did not recover. Drinking to carbachol by the LSN-lesioned animals also dropped significantly $30-\mathrm{min}$ postlesion $(p<.05)$, but had recovered by 5 days postlesioning. Prelesion drinking scores were different between groups $(p<.05)$.

\section{DISCUSSION}

The findings of this study compare Eavorably with those reported by Wolf \& Miller (1964). It is interesting to note, however, that since none of the LHA-lesioned sites in the present study were cholinergically positive, the production of the LHA syndrome and the effect on carbachol drinking probably cannot be explained in terms of direct damage to the cholinergic circuit itself. How lesions in the LHA affect the circuit and block drinking remains unclear. Wolf and Miller suggest that the absence of peripheral stimuli in the central elicitation of thirst might account for its inability to recover; peripheral stimuli presumably play a role in the reappearance of natural thirst. The LHA sites lesioned in this study, although not included within the primary circuit, could possibly act in a manner similar to the ventral amygdala, also outside the circuit, but which exerts a facilitatory effect on it (Grossman, 1964).

The reduction of cholinergic drinking immediately following lesioning in the LSN was unexpected since no reduction was found after unilateral lesions of the LSN. I This effect may have been due to the additional trauma caused by the bijateral lesions or possibly to rerouting of neural functions to other circuit structures following bilateral lesions.

\section{REFERENCES}

ANAND, B. K., \& BROBECK, J. R. Hypothalamic control of food intake in cats and rats. Yaje Journal of Biology \& Medicine, 1951, 24, 123.

FISHER, A. E., COURY, J. N. Cholinergic tracing of a central neural circuit underlying the thirst drive. Science, $1962,138,691-693$.

FISHER, A. E., \& COURY, J. N. Chemical tracing of neural pathways mediating the thirst drive. In $M \quad J$, Wayner (Ed.), Thirst. New York: Pergamon Press, 1964. Pp. 515-529.

GROSSMAN, S. P. Eating or drinking elicited by direct adrenergic or cholinergic stimulation of the hy p ot halamus. Science, 1960,132 . 301-302.

GROSSMAN, S. P. Some neurochemical properties of the central regulation of thirst. In M. J. Wayner (Ed.), Thirst. New York: Pergamon Press, 1964. Pp. 487.511.

LEVITT, R. A., \& FISHER, A. E. Anticholinergic blockade of centrally induced thirst. Science, 1966, 154. 520-522.
MILLER, N. E. Chemical coding of behavior in the brain. Science, $1965,148$. 328-338.

TEITELBAUM, P.. \& EPSTEIN, A. N. The lateral hypothalamic syndrome: Recovery of feeding and drinking after lateral hypothalamic lesions. Psychological Review, 1962, 69, 74-90.

WOLF, G.. \& MILLER, N, E. Lateral hypothalamic lesions: Effects on drinking elicited by carbachol in preoptic area and posterior hypothalamus. Science, 1964. 143, 585-587.

NOTE

1. Stein, G. W., \& Levitt, R. A. Lesion effects on cholinergically elicited drinking in the rat. in preparation.

\title{
Sucrose concentration and the magnitude of approach in a conflict situation*
}

\author{
WAYNE L. WAAG, DOLORES M. TYLER, and JOE W. DARNALL† \\ Texas Tech University, Lubbock, Tex. 79409
}

Three groups, each containing eight rats on 23-h water deprivation, were trained in a straight alley runway. During acquisition, Group 1 received distilled water as a reinforcer, Group 2 a $4 \%$ sucrose solution, and Group 3 a $16 \%$ sucrose solution. Following acquisition, Ss received shock as they entered the goalbox. A derived measure of approach magnitude was obtained for 4 successive days of conflict testing. Significant differences were obtained on Day 1, indicating the magnitude of approach to be greater for those groups receiving a sugar solution as a reinforcer.

Miller (1959) has suggested that the magnitude of the approach component in an approach-avoidance conflict situation is a result of three major variables: drive strength, defined in terms of the number of hours of deprivation; the number of reinforced trials during acquisition of the approach response; and the amount of reinforcement presented on each training trial. Within the conflict paradigm, experimental evidence has been reported which supports the first two of these proposed relationships. Miller (1944) and Brown (1948) found that increases in the length of deprivation resulted in a heightening of the approach gradient. Kaufman \& Miller (1949) reported that the percentage of animals that reached the goal following shock was a function of the number of previous training trials reinforced with food. The effects of the third variable, amount of reinforcement, is the primary concern of this study. Since amount and quality of reinforcement generally have the same effect upon acquisition

*This research was supported by THEMIS Contract No. DAAD05-69-C-0102, between the U.S. Department of Defense and Texas Tech University, R. A. Dudek. Project Manager. The contents do not necessarily reflect the official opinion or policy of the Department of Defense or the Department of the Army. Reproduction is authorized for any purpose of the U.S. Government.

tNow at the University of Indiana Medical School. Indianapolis, Indiana. performance, it was hypothesized that increases in the quality of reinforcement, as determined by level of sucrose concentration, would result in an increase in magnitude of the approach component in an approach-avoidance conflict situation. SUBJECTS

The Ss were 30 male albino rats of the Holtzman strain. They were approximately 110 days old at the beginning of the experiment.

\section{APPARATUS}

The apparatus was a straight-alley runway, 6 in. wide and 6 in. high throughout, which contained an $8-\mathrm{ft}$ open runway and a 6-in. goalbox. The runway portion had a movable floor consisting of $166 \times 6 \mathrm{in}$. wooden blocks. Beneath each block was a microswitch, which, when depressed, activated a separate pen of a 20-channel Esterline Angus event recorder. The pens in the recorder were sequenced so that they corresponded to the sequence of blocks within the alley. In this manner, the exact position of the animal at any time could be determined. The goalbox floor was a grid constructed from brass welding rods spaced $1 / 2$ in. apart, through which a $200-\mathrm{V}$ shock could be delivered by a Gerbrands shock generator. The end of the goalbox was a translucent piece of Plexiglas through which a lick tube extended approximately 1 in. above the grid. Three different lick tube 
assemblies were used for each of the three reinforcement conditions. Two measures of runway performance were recorded by electric clocks. Start latency was defined to be the time from the placement of the animal in the startbox until the depression of the microswitch under the fifth wooden block, which was 24 in. from the start end of the runway. Run time began with the depression of the fifth microswitch and ended with the depression of the last block. Diffused illumination was maintained throughout the course of the experiment.

\section{PROCEDURE}

Predeprivation water consumption was measured for 20 days. Ss were then matched in terms of their mean water consumption and randomly assigned to one of three groups. After 3 days of 23-h water deprivation, pretraining procedures began. On Day 1, each animal was confined to the goalbox by means of a stop block and remained until he drank from the lick tube. The animal was then removed from the goalbox, and the procedure was repeated again. On the third trial, the stop block was moved back 12 in. toward the startbox. On Day 2 of pretraining, the stop block was placed 12 in. from the goalbox on the first trial and $30 \mathrm{in}$. on the second and third trials. On Day 3, the stop block was placed 30 in. from the goal on Trial 1 and $42 \mathrm{in.}$ on Trial 2. The third trial required the animal to travel the entire distance of the runway. During acquisition training, each $S$ was run five trials a day with an intertrial interval of $15 \mathrm{sec}$. Group 1 received distilled water for reinforcement. Group 2 a $4 \%$ sucrose solution, and Group 3 a $16 \%$ sucrose solution. Acquisition lasted for 12 days, giving a total of 60 trials per animal. On Day 1 of conflict testing, Ss first received two acquisition trials. On the third trial, the grid was electrified so that $S$ received a shock upon entering the goalbox. The shock remained on until the animal ran toward the start end of the alley. Following shock, the animal remained in the runway until either he recovered and entered the goalbox, or until $4 \mathrm{~min}$. had elapsed. For the next 3 days, Ss were placed in the startbox for one trial and remained in the alley for $4 \mathrm{~min}$, or until they entered the goalbox. Graphical records of the animal's activity within the alley were obtained during each of the four conflict testing sessions. Upon being shocked, six Ss "froze" for the remainder of the initial $4-\mathrm{min}$ period as well as for the subsequent 3 days of conflict testing. These six animals were eliminated from the final data analysis thus making a total of eight Ss per group.

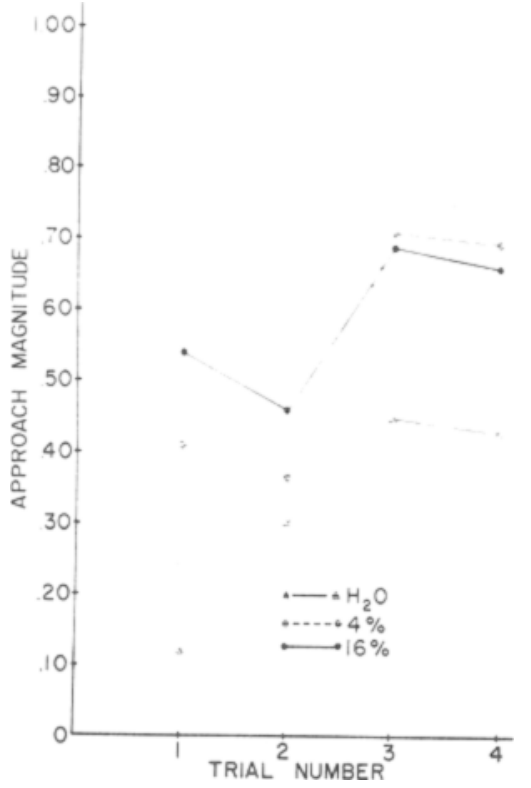

Fig. 1. Mean approach magnitude on the 4 days of conflict testing.

\section{RESULTS}

One-way analyses of variance were performed on the last block of 10 trials for both sets of acquisition data. The overall difference among the three groups was significant for both start time $[F(2,21)=5.46, p<.05]$ and run time $[F(2,21)=9.66, p<.01]$. A Tukey's HSD test (Kirk, 1968) for pairwise comparisons indicated both start and run time were significantly faster for animals run to a sucrose reward. However, there were no differences between the two sugar-reward groups.

It was assumed that the magnitude of the approach component would be manifested in the proportion of time spent by each $S$ in the end of the alley near the goalbox. From this assumption, the following measure was derived: $\quad \mathbf{A P}=(240-\mathrm{T}) / 240$, where $\mathrm{AP}=$ the magnitude of approach and $\mathrm{T}$ $=$ the time spent in the first three-quarters of the runway. The constant, 240, represented the total possible time in the runway. The resulting measure has a range from 0 to 1 and corrects for the case in which $S$ enters the goalbox before the end of the 4-min session. If only percentage of total time in the last quarter section of the runway had been used, it would have been possible for an animal to enter the goalbox rapidly and produce a score indicating a low magnitude of the approach component.

Figure 1 presents this derived measure for each of the three groups over the 4-day test period. Due to lack of homogeneity, a median test was applied to the data for all groups on Day 1. The results yielded a chi square of 16.0 ( $\mathrm{p}<.001)$. indicating signjificant dilferences between the medians of the three groups. Median tests applied to the data on the other 3 days of conflict testing were all nonsignificant.

\section{DISCUSSION}

A problem inherent in all experimental studies of conflict is that of obtaining an adequate measure of the magnitude of the approach and avoidance components. Many investigations have used simple start latency as a measure. However, it is often observed that animals with a short starting time approach the goalbox rapidly, begin to oscillate, and remain doing so until the end of the session. Other Ss may take more time in leaving the startbox, traverse the runway more slowly, yet enter directly into the goalbox. Such observations question the validity of start latency as a measure of the magnitude of approach. What is required is a measure which takes into account S's behavior for the entire period during which he is in the runway. The index used in this particular investigation represents at best a crude approximation to such an ideal measure. Nevertheless, it does have the advantage of adjusting for the total time which the animal spends in the runway.

The results using this derived measure support, at least in part, the contention that increases in sucrose concentration result in an increase in the magnitude of the approach component. From Fig. 1 it is apparent that the sugar-reward groups' performance was superior to that of the water-reward group. The wide variability among Ss necessitated the use of a distribution-free statistic which produced highly significant differences. It is apparent that research is needed to ascertain if reliable individual differences exist which might account for the observed variability.

\section{REFERENCES}

BROWN. J. S. Gradients of approach and avoidance responses and their relation to level of motivation. Journal of Comparative \& Physiological Psychology. $1948,41,450-465$

KAUFMAN, E. L.. \& MILLER. N. E. Effect of number of reinforcements on strength of approach in an approach-avoidance conflict. Journal of Comparative \& Physiological Psychology. 1949, 42. 65-74.

KIRK. R. E. Experimental design Procedures for the behavioral sciences. Belmont, Calif: Brooks-Cole, 1968.

MILLER, N. E. Expcrimental studies of conflict. In J. McV. Hunt (Ed) Personality and the behavior disorders. New York: Ronald, 1944

MLLER, N. E. Liberalization of basic S.R concepts: Extensions to conflict behavior, motivation, and social learning. In S. Koch (Ed.), Psychology, a study of a science. vol. 2 . New rork: McGraw-Hill, 1959. 